\title{
Influence of Packaging and Storage Conditions on the Quality and Shelf-life of Chewy Santol (Kraton-Yee) Candies
}

\author{
Phanida Renumarn ${ }^{1, *}$ and Natthaya Choosuk $^{1}$ \\ ${ }^{1}$ Department of Innovation and Product Development Technology, Faculty of Agro-Industry, King Mongkut's University of \\ Technology North Bangkok, Thailand
}

\begin{abstract}
In the present study, influence of two types packaging (inflated polypropylene (IPP) and laminated aluminium foil (ALU)) and storage conditions (with/without $1 \mathrm{~g}$ of silica desiccant packets (SDPs)) on quality and shelf life of chewy santol candies were studied. After storage at 25 degrees Celsius for 30 days, it was found that the combination of ALU with SDPs presented the best treatment to maintain the quality of colour, water activity $\left(a_{\mathrm{w}}\right)$, moisture content, total acidity, $\mathrm{pH}$ value, sensory evaluation i.e. (colour, odour, flavour and overall acceptance). Shelf-life prediction by using accelerated $\mathrm{Q}_{10}$ method based on moisture factors as an indicator of deterioration of the samples during storage. The samples were incubated at 25,35 and $45^{\circ} \mathrm{C}$ and sampled every 5 days for estimated on physical, chemical quality and microbiological change. The predicted shelf life of chewy santol candies at $25^{\circ} \mathrm{C}$ of IPP and ALU packaging with SDPs using Q10 method were 25 and 27 days, respectively. However, the IPP and ALU packaging without SDPs, the products can be stored less than 25 days. SDPs provides a cheaper and easy method to keeping quality of the chewy santol candies. Therefore, the products with SDPs packaging can maintain the product quality during storage and has an acceptable quality to consumers.
\end{abstract}

\section{Introduction}

Santol fruit (Sandoricum koetjape Merr.), which belongs to the Meliaceae family, is a tropical fruit. It naturally grows and develops in warm climate areas in most parts of all tropical countries particularly in Philippines, Malaysia, Indonesia, Cambodia, Laos, Vietnam, Brunei, India and also Thailand [1]. Santol fruits are popular in either fresh consumption or processing into various food products. The flesh can also be eaten fresh and often dipped in salt or other spices. However, santol fruits contain high amount of moisture [1], making them highly perishable. In addition, the flesh of santol has an astringent taste. Thus, it is necessary to preservation by processing into various products (such as pickled fruit, jam, jelly, ice-cream and confectionery etc.) for value adding and shelf life extending and distribution.

According to [2], moisture content and water activity play an importance as critical parameters related to quality and shelf life of confectionery product. The chewy santol candies are popularly produced in Prachinburi province of Thailand. The processing of chewy santol candies, the fruits are peeled chemically. First, the seeds are removed and the rinds are boiled with salt. They are preserved in processed to candies for extending the shelf-life, as well as resulting in value added in products.

Shelf-life studies are used to reasonably determine and predict whether the food products remain safe and maintain qualities, including chemical and physical, microbiological properties, nutritional composition and also sensory qualities, such as attractive colours and textures that make them attract the attention of customers [3].

In term of shelf life studies, there are two methods of operations. First, the direct method involves storing the product under specific conditions for a period of longer time than its expected shelf life and regularly interval checking to see when it begins to spoilage. Second, the indirect method has two tests that allow prediction of shelf life without conducting a full-length storage trial, and is useful for products with a long shelf life. The $1^{\text {st }}$ indirect method uses a predictive model based on information from a database that predicts bacterial growth under specific conditions, which can then be used to calculate shelf life. The second method is an accelerated shelf life studies, which involves deliberately increasing the rate at which the product will spoilage, usually by increasing the storage temperature [4].

A tool used in accelerated studies is "the rule of ten," or $\mathrm{Q}_{10}$, which is the factor by which the rate of spoilage increases when the storage temperature is raised by $10^{\circ} \mathrm{C}$. The $\mathrm{Q}_{10}$ allows for the prediction of a product's shelf life under real-life conditions based on the results of testing conducted at high temperatures [5]. Silica desiccant packets (SDPs) is used as a desiccant in food and nonfood products. SDPs is an inert material, nontoxic, non-flammable, easily packed in sachets or bags and approved safe by FDA. Therefore, this study aimed to investigate the influence of packaging (inflated polypropylene (IPP) and laminated aluminium foil (ALU)) and storage conditions (with/without (SDPs)) on the quality and shelf life of chewy santol candies during accelerated storage.

\footnotetext{
* Corresponding author: phanida.r@agro.kmutnb.ac.th
} 


\section{Material and methods}

The assays were performed in the Laboratory of faculty of Agro-industry at King Mongkut's University of Technology North Bangkok, Prachinburi campus. The chewy santol candies samples (golden brown colour) were produced by Small and Medium Enterprise (SMEs) in Prachinburi province.

\subsection{The chewy santol samples}

The chewy santol candies samples with $10 \pm 2 \%$ (w.b.) moisture content was kindly provided from Punya Garden Inc., Prachinburi, Thailand and transported to the laboratory in $2 \mathrm{~h}$. Stored at $20^{\circ} \mathrm{C}$ until the experiment.

\subsection{Packaging and storage conditions}

The chewy santol candies samples were separated and packed in two types of commercial packages: inflated polypropylene (IPP) package and laminated aluminium foil (ALU) package and storage conditions with or without $1 \mathrm{~g}$ of silica desiccant packets (SDPs) on quality and shelf life of chewy santol candies products.

\subsection{Accelerated storage treatment}

For accelerated storage experiment, the samples were stored for 30 days at 25,35 and $45^{\circ} \mathrm{C}$, respectively. During storage, the samples were collected at regular intervals of 5 days and all the samples were used for the determination of colour, water activity, moisture content, titratable acidity, reducing sugar and total sugar content, ascorbic acid content, microbial populations and sensory evaluation.

\subsection{Physical analysis}

\subsubsection{Colour}

Changes in the colour of the chewy santol samples were determined by CIE colour scales $\left(L^{*}\right.$ represents lightness, $a^{*}$ represents the red $(+)$ to green $(-)$ axis and $b^{*}$ represents the yellow $(+)$ to blue $(-)$ ness) using Hunter Lab digital (Colorflex, USA). Calibration with black and white standards was performed before colour measurement. The total colour difference $(\Delta E)$ was estimated with following equation 1 :

$$
\Delta E=\left[\left(L_{0}{ }^{*}-L_{\mathrm{t}}{ }^{*}\right)^{2}+\left(a_{0}{ }^{*}-a_{\mathrm{t}}{ }^{*}\right)^{2}+\left(b_{0}{ }^{*}-b_{\mathrm{t}}{ }^{*}\right)^{2}\right]^{1 / 2}
$$

Where the $L_{0}{ }^{*}, a_{0}{ }^{*}$ and $b_{0}{ }^{*}$ index were measured from the samples at beginning of the storage $(\mathrm{t}=0)$ and the $L_{\mathrm{t}}{ }^{*}, a_{\mathrm{t}}{ }^{*}$ and $b_{\mathrm{t}}{ }^{*}$ index were measured from the storage samples at specific storage time.

\subsubsection{Water activity and moisture content}

The water activity $\left(a_{\mathrm{w}}\right)$ of the samples was measured at $25 \pm 1^{\circ} \mathrm{C}$ by water activity meter (Aqua Lab, model CX3TE,
USA) and the moisture content was determined by drying $1 \mathrm{~g}$ of the sample in hot air oven (Binder FD115, Germany) at $105^{\circ} \mathrm{C}$ to a constant weight [6]. The moisture content was calculated from the weight difference between the original and dried samples and expressed in percentage. The measured was done in triplicate.

\subsection{Chemical analysis}

\subsubsection{Titratable acidity}

Titratable acidity (TA) of samples was determined by titration method [7]. The homogenising $10 \mathrm{~g}$ of samples in $20 \mathrm{~mL}$ distilled water. The filtrate was obtained by passing the homogenized sample through a filter paper (Whatman paper No.4) and was used for TA determination. The suspension was titrated against $0.1 \mathrm{~N} \mathrm{NaOH}$ using phenolphthalein indicator (Standardized using standard oxalic acid). The end point was the colour changed from colourless to pale pink. Total acidity was calculated in terms of citric acid.

\subsubsection{Reducing sugar and total sugar content}

Reducing sugar and total sugar content were measured as monosaccharides using a modified dinitrosalicylic acid (DNS) colorimetric method [8]. The content of reducing sugars was measured by using spectrophotometrically at $540 \mathrm{~nm}$. Results were expressed as $\mathrm{mg}$ of glucose per $\mathrm{g}$ of chewy santol samples.

\subsubsection{Ascorbic acid content}

Ascorbic acid (AA) content was analysed according to the colorimetric method [6]. Metaphosphoric acid-acetic solution $(5 \mathrm{~mL})$ was pipette and added to a $2 \mathrm{~mL}$ ascorbic acid standard solution in triplicates. This was titrated against indophenols solution until a distinct rosepink colour formed and persisted for more than $5 \mathrm{~s}$. This initial and final reading of the burette were recorded. Blanks were prepared in the same way as above and the average titer of indophenols dye used was calculated.

\subsubsection{Microbial populations}

To measure the microbial populations of the chewy santol samples, a $25 \mathrm{~g}$ of samples were homogenized with $225 \mathrm{~mL}$ of $1 \%$ sterile peptone water using a Stomacher (Stomacher ${ }^{\circledR} 400$ Circulator, England) for $1 \mathrm{~min}$. Ten-fold dilution series were made in sterile peptone water as required for plating on (1) Plate Count Agar, PCA (HiMedia) incubated at $37 \pm 2{ }^{\circ} \mathrm{C}$ for $24 \pm 3 \mathrm{~h}$ for determining the total bacteria counts; (2) Potato dextrose agar (HiMedia) incubated at $28 \pm 2^{\circ} \mathrm{C}$ for 7 days for determining the yeast and mold counts. The microbial populations were expressed as log CFU/g sample (colony forming units per gram). All measurements were performed in triplicate.

\subsection{Sensory evaluation}

The sensory evaluation of the chewy santol candies samples in balanced incompletely block (BIB) design 
was carried out using a 50 local consumers composed of men and women, aged between 18 and 40 years. The samples were evaluated using a 9-point hedonic scale $(1=$ dislike extremely, $5=$ neither like nor dislike, $9=$ like extremely) to evaluate liking of colour, odour, flavour, texture and overall acceptability. Both the order of panellists and the sequence of samples in each plate were previously randomized to avoid statistical bias.

\subsection{Shelf life prediction of samples}

The product was shelf life predicted on the basis of an estimated rate of deterioration increases when the temperature is raised by $10^{\circ} \mathrm{C}\left(\mathrm{Q}_{10}\right)$. The $\mathrm{Q} 10$ approach is often used for estimation of the temperature acceleration of shelf life, which using the following equation 2 [5]:

$$
\mathrm{Q}_{10}=\text { Shelf life at } \mathrm{T}_{1} / \text { Shelf life at } \mathrm{T}_{1}+10^{\circ} \mathrm{C}
$$

Where $\mathrm{T}_{1}$ is temperature at ${ }^{\circ} \mathrm{C}$ which the testing in conducted.

For most products the $\mathrm{Q}_{10}$ value is 2.0, which means that for every increase of $10^{\circ} \mathrm{C}$, the rate of a chemical reaction will double [5].

The study was to evaluate shelf life index and accelerated shelf life of chewy santol products by using accelerated $\mathrm{Q}_{10}$. Products were incubated at 25, 35 and $45^{\circ} \mathrm{C}$ and products properties were measureed on physical, chemical quality and microbiological change.

\subsection{Statistical analysis}

Statistical analysis of all data were represented as mean \pm SD. Significance data were subjected to analysis of variance (ANOVA) based on Randomized Complete Block Design (RCBD), $P \leq 0.05$ using SPSS version 21.0 (SPSS Inc., Chicago, IL, USA). Duncan's multiple range test were used to evaluate the significance of differences. All the experiments were repeated for three times.

\section{Results and discussion}

\subsection{Physical analysis}

Physical parameters, such as colour, water activity $\left(a_{\mathrm{w}}\right)$ and moisture content are often measured in confectionary factories to control the degree of hydration and the qualities of samples during storage time. The colour analysis of chewy santol candies in difference packages and storage conditions during storage time were shown in Fig. 1. The results of $L^{*}, a^{*}$ and $b^{*}$ colour parameters were significantly affected $(P<0.05)$ by both package types and storage conditions. It was observed that the $L^{*}$ (Fig. 1A and 1B), $a^{*}$ and $b^{*}$ parameters $\left(a^{*}\right.$ and $b^{*}$ values data not shown) were decreased during longer time of storage, especially when stored at higher temperature resulting in the decrease of brightness and samples becomes darken. Moreover, $a^{*}$ values were also changed from 10.85 to 5.43 of storage at $45^{\circ} \mathrm{C}$ for 5 and 30 days of storage, respectively and $b^{*}$ values of 8.83 to 4.17 storage at $45^{\circ} \mathrm{C}$ for 5 and 30 days of storage, respectively. That is when chewy santol candies samples had change the colour from the brightness from 5 days of storage, they become getting darker at high temperature $\left(45^{\circ} \mathrm{C}\right)$ storage after 30 days. It may be related to nonenzymatic browning reactions, such as the Maillard reaction and caramelization at high temperatures. The Maillard reaction is a chemical reaction between amino acid groups and reducing sugars, and high temperature accelerates the reaction resulting in changes in the aroma, taste and colour of foods [9]. This reaction may be an effective way to increase or decrease the acceptability of chewy santol candies products.
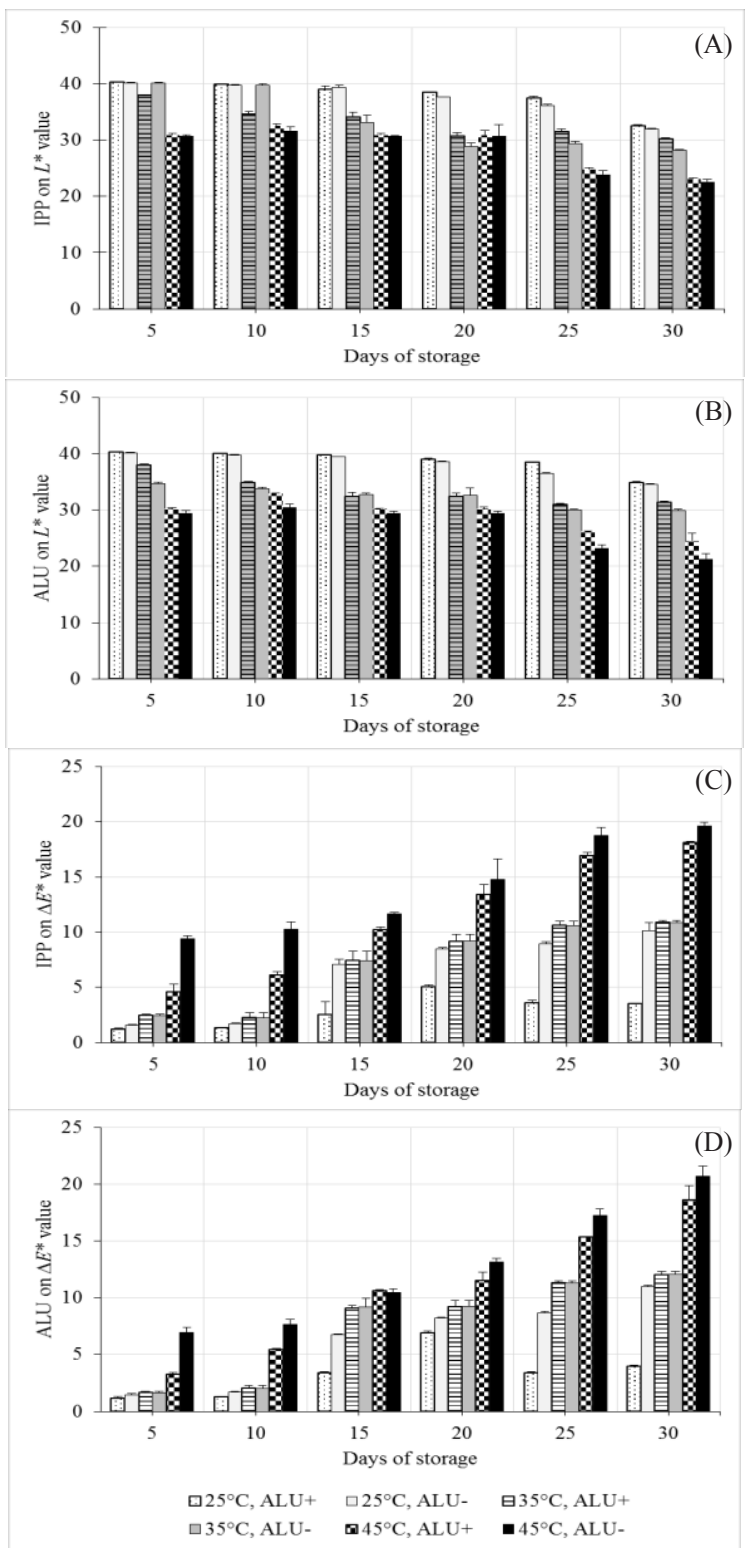

Fig. 1. Changes in colour* ( $L^{*}$ and $\Delta E^{*}$ value) of chewy santol candies samples during storage at 25,35 and $45^{\circ} \mathrm{C}$ for 30 days. Data shown are mean values of $n=6$ and the error bars represent standard deviation using Duncan's multiple range test at $P \leq 0.05$. Where IPP + is inflated polypropylene (IPP) package with SDPs; IPP - is inflated polypropylene (IPP) package without SDPs; ALU+ is laminated aluminium foil (ALU) with SDPs; ALU- is laminated aluminium foil (ALU) without SDPs; SDPs is silica desiccant packets. 
The total colour difference ( $\Delta E$ value) was measured to evaluate changes of the colour difference based on $L^{*}$, $a^{*}$ and $b^{*}$ values. The $\Delta E$ value between difference of package and storage conditions of chewy santol candies samples were generally higher for higher storage temperature during storage (Fig. 1C). The results indicated that samples, kept at higher storage temperature $\left(45^{\circ} \mathrm{C}\right)$, had higher $\Delta E$ value than the samples that contain SDPs at lower storage temperature $\left(25^{\circ} \mathrm{C}\right)$. This may be due to the SDPs with low storage temperature decreasing colour change reaction. The $\Delta E$ values were 1.18 and 6.96 in ALU package with SDPs for 5 and 30 days of storage, respectively. Importantly, the ALU package with SDPs treatment showed the lowest $\Delta E$ value, which expressed the lowest value of total colour change.

The physical parameters by the water activity $\left(a_{\mathrm{w}}\right)$ and moisture content of chewy santol candies samples were given in Table 1 and 2. After 5-day storage, the water activities $\left(a_{\mathrm{w}}\right)$ were not significantly affected $(P>0.05)$ by difference of packaging and storage condition, and they were slightly decreasing during storage time. The average values of $a_{\mathrm{w}}$ of samples ranged from 0.393 to 0.419 . A previous study reported the water activity $\left(a_{w}\right)$ of gummy candies was reported as 0.54 to 0.68 [10]. One of the most important factor to determine shelf life of confectionery products is $a_{w}$. In addition, $a_{w}$ is not only determined by the total quantity of water in products but it is susceptible to microbial spoilage in most confectionery products [11].

Table 1. Effect of package and storage condition on water activity $\left(a_{\mathrm{w}}\right)$ at three different temperatures during storage time.

\begin{tabular}{|c|c|c|c|}
\hline \multirow{2}{*}{$\begin{array}{c}\text { Package } \\
\text { types }\end{array}$} & \multirow{2}{*}{$\begin{array}{c}\text { Temperature } \\
\left({ }^{\circ} \mathrm{C}\right)\end{array}$} & \multicolumn{2}{|c|}{ Water activity $\left(a_{\mathrm{w}}\right)$} \\
\hline & & 5 days ${ }^{\mathrm{NS}}$ & 25 days \\
\hline $\operatorname{IPP}(+)$ & 25 & $0.415 \pm 0.005$ & $0.381 \pm 0.000^{\mathrm{b}}$ \\
\hline $\operatorname{IPP}(-)$ & 25 & $0.419 \pm 0.005$ & $0.385 \pm 0.000^{\mathrm{a}}$ \\
\hline $\operatorname{IPP}(+)$ & 35 & $0.412 \pm 0.005$ & $0.377 \pm 0.001^{\mathrm{c}}$ \\
\hline $\operatorname{IPP}(-)$ & 35 & $0.415 \pm 0.008$ & $0.381 \pm 0.004^{b}$ \\
\hline $\operatorname{IPP}(+)$ & 45 & $0.409 \pm 0.001$ & $0.367 \pm 0.000^{\mathrm{f}}$ \\
\hline $\operatorname{IPP}(-)$ & 45 & $0.414 \pm 0.002$ & $0.366 \pm 0.000^{\mathrm{f}}$ \\
\hline $\operatorname{ALU}(+)$ & 25 & $0.414 \pm 0.000$ & $0.380 \pm 0.004^{\mathrm{b}}$ \\
\hline $\operatorname{ALU}(-)$ & 25 & $0.415 \pm 0.001$ & $0.376 \pm 0.000^{c}$ \\
\hline $\operatorname{ALU}(+)$ & 35 & $0.409 \pm 0.002$ & $0.376 \pm 0.000^{\text {cd }}$ \\
\hline $\operatorname{ALU}(-)$ & 35 & $0.415 \pm 0.001$ & $0.370 \pm 0.001^{\mathrm{e}}$ \\
\hline $\operatorname{ALU}(+)$ & 45 & $0.414 \pm 0.002$ & $0.371 \pm 0.000^{\mathrm{e}}$ \\
\hline $\operatorname{ALU}(-)$ & 45 & $0.393 \pm 0.001$ & $0.374 \pm 0.000^{\mathrm{d}}$ \\
\hline
\end{tabular}

Where IPP+ is inflated polypropylene (IPP) package with SDPs; IPPis inflated polypropylene (IPP) package without SDPs; ALU+ is laminated aluminium foil (ALU) with SDPs; ALU- is laminated aluminium foil (ALU) without SDPs; SDPs is silica desiccant packets. Means with different superscripts are different at $P \leq 0.05$ between treatments ( \pm standard deviation of the mean).

NS: not significant.

In contrast, moisture contents of samples were significantly $(P<0.05)$ affected by difference of packaging and storage condition, and they increased dramatically until the end of storage, the average values of moisture contents of samples ranged from 11.59 to $17.74 \%$ (Table 2). After accelerated storage for 25 days, the samples in ALU package with SDPs had 17.10 $\pm 0.07,17.23 \pm 0.03$ and $17.42 \pm 0.02 \%$ of moisture at 25,35 and $45^{\circ} \mathrm{C}$, respectively. The end of product storage that indicated by moisture content to Standard configuration according to Thai Community Product Standard (TCPS) (TCPS on spicy candied fruits and vegetables), must has a moisture content no greater than $18 \%$ dry weight. In previous study, moisture contents of jelly candies were reported as 20.05 to $25.68 \%$ [12].

Table 2. Effect of package and storage condition on moisture content at three different temperatures during storage time.

\begin{tabular}{cccc}
\hline $\begin{array}{c}\text { Package } \\
\text { types }\end{array}$ & $\begin{array}{c}\text { Temperature } \\
\left({ }^{\circ} \mathbf{C}\right)\end{array}$ & \multicolumn{2}{c}{ Moisture content (\%) } \\
\cline { 3 - 4 } & 25 & $11.59 \pm 0.34^{\mathrm{e}}$ & $17.32 \pm 0.05^{\mathrm{e}}$ \\
\hline $\mathrm{IPP}(+)$ & 25 & $12.26 \pm 0.03^{\text {cd }}$ & $17.56 \pm 0.04^{\mathrm{c}}$ \\
$\mathrm{IPP}(-)$ & 35 & $12.11 \pm 0.07^{\mathrm{d}}$ & $17.43 \pm 0.01^{\mathrm{d}}$ \\
$\mathrm{IPP}(+)$ & 35 & $12.55 \pm 0.03^{\mathrm{bc}}$ & $17.65 \pm 0.02^{\mathrm{b}}$ \\
$\mathrm{IPP}(-)$ & 45 & $12.27 \pm 0.10^{\mathrm{cd}}$ & $17.51 \pm 0.01^{\mathrm{c}}$ \\
$\mathrm{IPP}(+)$ & 45 & $12.69 \pm 0.05^{\mathrm{ab}}$ & $17.74 \pm 0.03^{\mathrm{a}}$ \\
$\mathrm{IPP}(-)$ & 25 & $11.66 \pm 0.06^{\mathrm{e}}$ & $17.10 \pm 0.07^{\mathrm{g}}$ \\
$\mathrm{ALU}(+)$ & 25 & $12.45 \pm 0.25^{\mathrm{bc}}$ & $17.45 \pm 0.55^{\mathrm{d}}$ \\
$\mathrm{ALU}(-)$ & 35 & $12.03 \pm 0.04^{\mathrm{d}}$ & $17.23 \pm 0.03^{\mathrm{f}}$ \\
$\mathrm{ALU}(+)$ & 35 & $12.92 \pm 0.47^{\mathrm{a}}$ & $17.54 \pm 0.01^{\mathrm{c}}$ \\
$\mathrm{ALU}(-)$ & 45 & $12.16 \pm 0.18^{\mathrm{d}}$ & $17.42 \pm 0.02^{\mathrm{d}}$ \\
$\mathrm{ALU}(+)$ & 45 & $12.85 \pm 0.02^{\mathrm{a}}$ & $17.66 \pm 0.03^{\mathrm{b}}$ \\
\hline ALU (-) & & &
\end{tabular}

Where IPP+ is inflated polypropylene (IPP) package with SDPs; IPPis inflated polypropylene (IPP) package without SDPs; ALU+ is laminated aluminium foil (ALU) with SDPs; ALU- is laminated aluminium foil (ALU) without SDPs; SDPs is silica desiccant packets. Means with different superscripts are different at $P \leq 0.05$ between treatments ( \pm standard deviation of the mean)

\subsection{Chemical analysis}

Chemical parameters, such as titratable acidity (TA), reducing sugar and total sugar content, ascorbic acid (AA) content (Fig. 2) and microbial populations (Table 3) were often evaluated as an indicators of products quality during storage.

The titratable acidity (TA) of samples were significantly affected $(P<0.05)$ by difference of packaging and storage condition. The results showed that the overall trend of TA seemed slightly increasing in all treatments during storage time at $25^{\circ} \mathrm{C}$, with the exception of results of day 10 at $25^{\circ} \mathrm{C}$. The average values of TA of samples ranged from 0.14 to $0.27 \mathrm{~g} / \mathrm{L}$ citric acid equivalent (Fig. 2A). It was reported that a gradual increase in TA value during storage in carrot candy [13]. However, the package with SDPs samples had lower TA values than their package without SDPs samples.

The averages of reducing sugar contents (data not shown) and total sugar contents were presented in Fig. 2B. It was determined that total sugar contents and reducing sugar contents were significant affected $(P<0.05)$ by difference of packaging and storage condition, and they slightly decreased during storage time, the average values of total sugars contents and reducing sugar contents of samples ranged from 309.27 to 488.22 and 231.24 to $442.01 \mathrm{mg} / \mathrm{g}$ sample, respectively. The reduction of both total sugar contents and reducing sugar contents may be as a result of non-enzymatic browning reactions, such as the Maillard reaction during storage [14]. 
The ascorbic acid content (AA) of samples were similar trend in all treatments, and they slightly decreased during storage time, the average values of AA of samples ranged from 129.43 to $159.92 \mathrm{mg}$ ascorbic acid/10 g sample (Fig. 2C). The loss of AA contents was observed during the storage of chewy santol candies in all treatments. This study showed that either the packaging material or the SDPs had non-significant effect on AA changes.
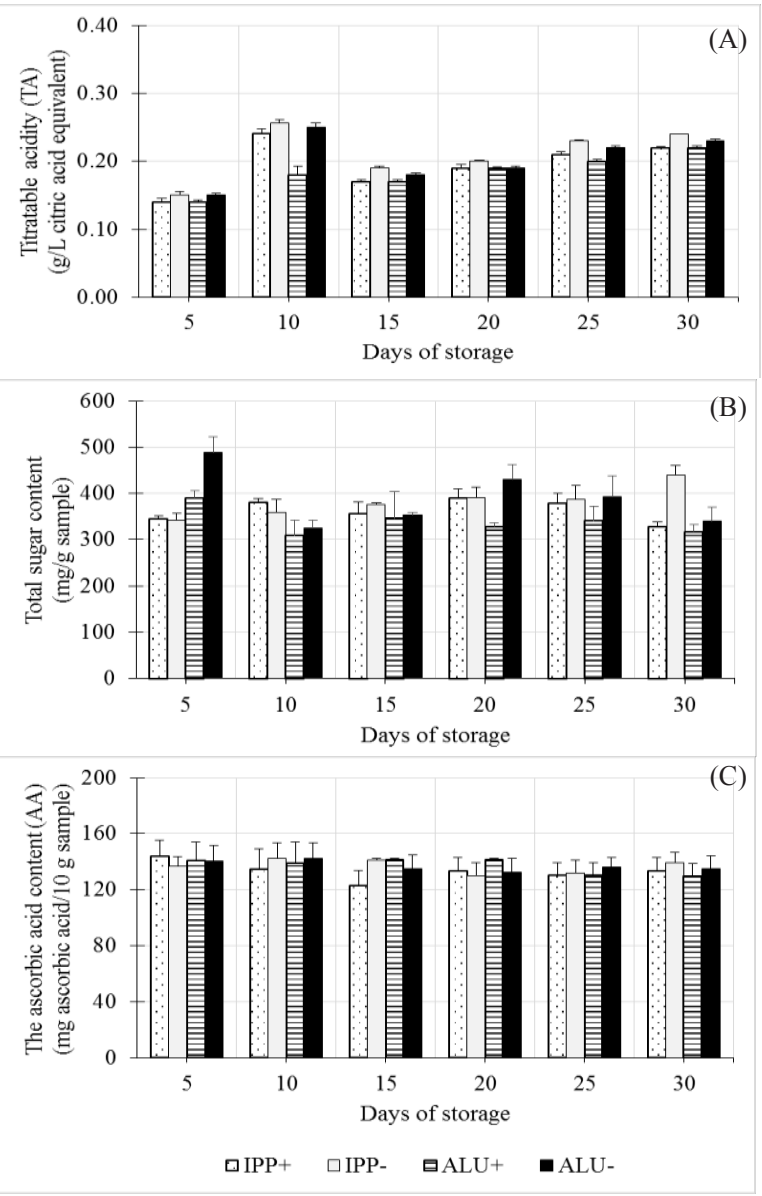

Fig. 2. Changes in titratable acidity (A), total sugar content (B) and ascorbic acid content (C) of chewy santol candies samples during storage at $25^{\circ} \mathrm{C}$ for 30 day. Data shown are mean values of $n=6$ and the error bars represent standard deviation using Duncan's multiple range test at $P \leq 0.05$. Where IPP + is inflated polypropylene (IPP) package with SDPs; IPP- is inflated polypropylene (IPP) package without SDPs; ALU+ is laminated aluminium foil (ALU) with SDPs; ALU- is laminated aluminium foil (ALU) without SDPs; SDPs is silica desiccant packets.

Microbial population after 30 days of storage were shown in Table 3. No microbial growth was detected in all samples stored at 25,35 and $45^{\circ} \mathrm{C}$ for 15 day after storage (data not shown). This result indicated good manufacturing practice in the preparation of chewy santol candies products. Furthermore, after 30 days of storage, this study found that samples had the lowest total bacterial counts (2.77 to $3.45 \log \mathrm{CFU} / \mathrm{g}$ sample). In addition, the yeast and mould counts were below the acceptable levels in all samples analysed during storage (below $1.59 \log \mathrm{CFU} / \mathrm{g}$ ). Comparing the results obtained from different types of package and storage conditions at each temperature, no significant differences were found in yeast and mold populations. Moreover, the final results showed that the presence of total bacteria, yeast and mold counts were not exceeding the Standard configuration according to Thai Community Product Standard (TCPS) (TCPS on spicy candied fruits and vegetables). In addition, Salmonella spp. and Escherichia coli (E. coli) were not detected in the products (data not shown).

Table 3. Effect of package and storage condition on total bacteria and yeast and mold counts (log CFU/g sample) at three different temperatures after 30 days of storage.

\begin{tabular}{cccc}
\hline $\begin{array}{c}\text { Package } \\
\text { types }\end{array}$ & $\begin{array}{c}\text { Temp. } \\
\left({ }^{\circ} \mathbf{C}\right)\end{array}$ & $\begin{array}{c}\text { Total bacteria } \\
\text { counts } \\
(\mathbf{l o g} \text { CFU/g) }\end{array}$ & $\begin{array}{c}\text { Yeast and mold } \\
\text { counts } \\
(\log \text { CFU/g) })^{\mathrm{NS}}\end{array}$ \\
\hline $\mathrm{IPP}(+)$ & 25 & $2.85 \pm 0.20^{\mathrm{cd}}$ & $1.59 \pm 1.43$ \\
$\mathrm{IPP}(-)$ & 25 & $3.15 \pm 0.18^{\mathrm{b}}$ & $\mathrm{ND}$ \\
$\mathrm{IPP}(+)$ & 35 & $3.15 \pm 0.15^{\mathrm{b}}$ & $0.86 \pm 1.50$ \\
$\mathrm{IPP}(-)$ & 35 & $3.16 \pm 0.03^{\mathrm{b}}$ & $\mathrm{ND}$ \\
$\mathrm{IPP}(+)$ & 45 & $3.22 \pm 0.10^{\mathrm{ab}}$ & $\mathrm{ND}$ \\
$\mathrm{IPP}(-)$ & 45 & $2.77 \pm 0.17^{\mathrm{d}}$ & $\mathrm{ND}$ \\
$\mathrm{ALU}(+)$ & 25 & $3.18 \pm 0.17^{\mathrm{b}}$ & $\mathrm{ND}$ \\
$\mathrm{ALU}(-)$ & 25 & $3.29 \pm 0.11^{\mathrm{ab}}$ & $\mathrm{ND}$ \\
$\mathrm{ALU}(+)$ & 35 & $3.08 \pm 0.10^{\mathrm{bc}}$ & $0.76 \pm 1.32$ \\
$\mathrm{ALU}(-)$ & 35 & $3.45 \pm 0.14^{\mathrm{a}}$ & $\mathrm{ND}$ \\
$\mathrm{ALU}(+)$ & 45 & $3.04 \pm 0.03^{\mathrm{bc}}$ & $0.66 \pm 1.15$ \\
ALU (-) & 45 & $3.07 \pm 0.12^{\mathrm{bc}}$ & $0.76 \pm 1.32$ \\
\hline
\end{tabular}

Where IPP+ is inflated polypropylene (IPP) package with SDPs; IPPis inflated polypropylene (IPP) package without SDPs; ALU+ is laminated aluminium foil (ALU) with SDPs; ALU- is laminated aluminium foil (ALU) without SDPs; SDPs is silica desiccant packets. Means with different superscripts are different at $P \leq 0.05$ between treatments ( \pm standard deviation of the mean). NS: not significant.

\subsection{Sensory evaluation}

The sensory evaluation of the chewy santol candies products was conducted on colour, odour, flavour, texture and overall acceptability (data not shown). Ranking scores of all sensory attributes of the samples were slightly decreased during the storage period. However, according to results, the samples in ALU package with SDPs at $25^{\circ} \mathrm{C}$ for the end of storage $(25$ days) got more than 6.29 on 9-point hedonic scale, indicating that ALU package with SDPs can maintain the acceptable consumer quality for 25 days.

\subsection{Shelf life prediction of samples}

The predicted shelf life of chewy santol candies samples on IPP and ALU packaging with/without SDPs storage at $25^{\circ} \mathrm{C}$ using Q10 method were shown in Table 4 . Results indicated that the higher in moisture content, the shorter the shelf life. In other words, the shelf life of the chewy santol candies samples in IPP or ALU packages with SDPs were longer than the shelf life of the chewy santol candies samples without SDPs. 
Table 4. The predicted shelf life of chewy santol candies samples on IPP and ALU packaging with/without SDPs storage at $25^{\circ} \mathrm{C}$ using Q10 method

\begin{tabular}{ccc}
\hline Temperature $\left({ }^{\circ} \mathbf{C}\right)$ & Package types & Shelf life (Days) \\
\hline 25 & IPP $(+)$ & 27 \\
25 & IPP $(-)$ & 25 \\
25 & ALU $(+)$ & 27 \\
25 & ALU $(-)$ & 25 \\
\hline
\end{tabular}

Where IPP+ is inflated polypropylene (IPP) package with SDPs; IPPis inflated polypropylene (IPP) package without SDPs; ALU+ is laminated aluminium foil (ALU) with SDPs; ALU- is laminated aluminium foil (ALU) without SDPs; SDPs is silica desiccant packets.

\section{Conclusion}

This study investigated the effect of different packages and storage conditions (with/without (SDPs)) on the quality of the chewy santol candies samples during storage time. Although ALU packaging with SDPs resulted in slight change in colour, water activity $\left(a_{\mathrm{w}}\right)$, moisture content, titratable acidity, ascorbic acid content and also maintained microbiological safety during storage time at $25^{\circ} \mathrm{C}$. While, IPP packaging without SDPs seemed a slightly degradation in quality of the chewy santol candies during storage time. Therefore, this study suggested ALU packaging with SDPs of chewy santol candies samples for maintain the quality preservation for 27 days.

This research was financially supported by King Mongkut's University of Technology North Bangkok. Contact no. KMUTNB59GEN-59-59.

\section{References}

1. J. Morton, Santol. Fruits of warm climates. 199-201 (1987),
2. R. Ergun, R. Lietha, R.W. Hartel, Crit. Rev. Food Sci. Nutr., 150(2), 162-192, (2010)

3. Shelf life of foods, "Guidelines for its determination and prediction", Institute of Food Science and Technology, London. (1993)

4. New Zealand Food Safety Authority, "A Guide to Calculating the Shelf Life of Foods: food", New Zealand Food Safety Authority, Wellington. (2005)

5. T.P. Labuza and M.K. Schmidl, J. Food Technol., 39(9), 57-64, (1985)

6. AOAC., Official methods of analysis (International $9^{\text {th }}$ ed. Williams, S.). Association of Analytical Chemists, Washington, DC., USA. (2000)

7. AOAC., Official methods of analysis (International $16^{\text {th }}$ ed. Williams, S.). Association of Analytical Chemists, Washington, DC., USA. (2002)

8. E.H. Fisher and E.A. Stein, Biochem. Prep., 8, 3037, (1961)

9. S.I.F.S. Martins, W.M.F. Jongen, M.A.J.S. Van Boekel, Trends Food Sci Tech., 11, 364-373, (2000)

10. S. Amjadi, M. Ghorbani, H. Hamishehkar, L. Roufegarinejad, Food Chemistry, 256, 156-162, (2018)

11. T.J. Hansen, Chapter 7: Candy and sugar confectionery. Handbook of Food and Beverage Stability. Charalambous G. (Eds.),. Food Sci. Technol, 423-465, (1986)

12. C. Mutlu, S.A. Tontul, M. Erbaş, LWT- J. Food Sci. Technol, 93, 499-505, (2018)

13. A.M. Durrani, P.K. Srivastava, S. Verma, J. Food Sci. Technol, 48(4), 502-505, (2011)

14. C. Schebor, L. Burin, M. Pilar-Buera, J. Chirife, LWT- J. Food Sci. Technol, 32(8), 481-485, (1999) 